\title{
A Study to Evaluate the Effectiveness of Structured Instructional Program on Practice Regarding Selected Home Based Newborn Care among Mother Under Cesarean Section in Baghdad Teaching Hospital
}

\author{
Rabea Mohsen Ali ${ }^{1}$, Sarab Nasr Fadhil ${ }^{1}$, Amal Kalfkadhum ${ }^{2}$ \\ ${ }^{1}$ PhD, Maternal and Neonate Nursing Department, College of Nursing/University of Baghdad, Iraq, \\ ${ }^{2}$ M.Sc., Karbalaa Health Directorate
}

\begin{abstract}
The study aims to evaluate the Effectiveness of Structured Instructional Program on Practice regarding Selected Home based Newborn Care among Mother under Cesarean Section. A quasi-experimental study design was conducted during the period of $\left(15^{\text {th }}\right.$ January 2014 through $15^{\text {th }}$ May 2014) on non-probability of (100) women (50) of them were a control group and (50) were the study group whom admitted to maternity department at Baghdad Teaching Hospital in Baghdad city. A questionnaire was used as a tool of data collection Descriptive \& Inferential statistical analyses were used to analyze the data. The result of study indicate that highest percentages of study and control groups were in age group (20-34) years old, most of them illiterate, read and write, and primary schools graduates, housewife, from "urban area", the control and study groups accounted (62\%), and (68\%) at (3-4) (5-6) pregnancy. (38\%) \& (50\%) in control and study groups respectively are registered at (3-4) deliveries, and reported none abortion at (82\%) and $(84 \%)$ in control and study groups respectively .Also there are highly significant differences concerning the instructions care for their children during the postpartum period after cesarean section at the study group, as well as extremely good effectiveness for the instructions. The study recommended that nurses should teach women delivered by cesarean section the principle practice regarding newborn care, also recommended on mass media to take an action to keep the mother informed about practice regarding newborn care.
\end{abstract}

Keywords: Effectiveness, Practice, Newborn Care, Cesarean Section.

\section{Introduction}

The days and weeks following childbirth - the postnatal period - are a criticalphase in the lives of mothers and newborn babies. Most maternal and infant deaths occur in the first month after birth: almost half of postnatal maternal deaths occur within the first 24 hours, and $66 \%$ occur during the first week. The World Health Organization (WHO) recently updated global guidelines

\section{Corresponding Author:}

Sarab Nasr Fadhil

Instructor. Dr. College of nursing, University of

Baghdad, Iraq

e-mail: sarab@conursing.uobaghdad.edu.iq onpostnatal care for mothers and newborns through a technical consultation process.

The new guidelines address the timing and content of postnatal care for mothers and newborns with a special focus on resource-limited settings in low- and middle-income countries.

\section{Methodology}

A quasi-experimental study design was conducted on purposive sample, (100) women delivery by cesarean section in Baghdad teaching hospital. 50 Women considered as (study group) and another 50 women were control group whom admitted to Baghdad teaching Hospital. Study implemented for the period of $15^{\text {th }}$ January 2014 through $15^{\text {th }}$ May 2014. Data collection will be gathered by application session to women post 
cesarean section regarding home based newborn care which were designed and scheduled for approximately (60-90) minutes for each woman, and by used questionnaire format which consisted of three parts, Descriptive and inferential statistical analyses were used to analyze the data

\section{Results}

Table (1): Distribution of Socio - Demographical Characteristics variables in the studied groups

\begin{tabular}{|c|c|c|c|c|c|c|}
\hline \multirow{2}{*}{$\begin{array}{l}\text { Socio-Demographics } \\
\text { Variables }\end{array}$} & \multirow{2}{*}{ Groups } & \multicolumn{2}{|c|}{ Control } & \multicolumn{2}{|c|}{ Study } & \multirow{2}{*}{$\begin{array}{l}\text { C.S. (*) } \\
\text { P-value }\end{array}$} \\
\hline & & No. & $\%$ & No. & $\%$ & \\
\hline \multirow{6}{*}{ Age Groups } & $15-19$ & 1 & 2 & 2 & 4 & \multirow{6}{*}{$\begin{array}{c}\text { C.C. }=0.182 \\
\mathrm{P}=0.636 \\
\mathrm{NS}\end{array}$} \\
\hline & $20-24$ & 13 & 26 & 11 & 22 & \\
\hline & $25-29$ & 14 & 28 & 10 & 20 & \\
\hline & $30-34$ & 12 & 24 & 19 & 38 & \\
\hline & $35-39$ & 6 & 12 & 6 & 12 & \\
\hline & $40-44$ & 4 & 8 & 2 & 4 & \\
\hline \multirow{7}{*}{ Education level of wife } & Illiterate & 14 & 28 & 15 & 30 & \multirow{7}{*}{$\begin{array}{c}\text { C.C. }=0.133 \\
\mathrm{P}=0.937 \\
\mathrm{NS}\end{array}$} \\
\hline & Read and write & 14 & 28 & 14 & 28 & \\
\hline & Primary school & 15 & 30 & 14 & 28 & \\
\hline & Intermediate school & 2 & 4 & 1 & 2 & \\
\hline & Secondary school & 2 & 4 & 3 & 6 & \\
\hline & Institute & 1 & 2 & 0 & 0.0 & \\
\hline & College and more & 2 & 4 & 3 & 6 & \\
\hline \multirow{3}{*}{$\begin{array}{l}\text { Occupation status of } \\
\text { wife }\end{array}$} & House wife & 46 & 92 & 44 & 88 & \multirow{3}{*}{$\begin{array}{c}\text { C.C. }=0.142 \\
\mathrm{P}=0.360 \\
\mathrm{NS}\end{array}$} \\
\hline & Employee & 3 & 6 & 6 & 12 & \\
\hline & Student & 1 & 2 & 0 & 0.0 & \\
\hline \multirow{3}{*}{ Residency } & Rural & 6 & 12 & 9 & 18 & \multirow{3}{*}{$\begin{array}{c}\text { C.C. }=0.189 \\
\mathrm{P}=0.156 \\
\mathrm{NS}\end{array}$} \\
\hline & Urban & 32 & 64 & 36 & 72 & \\
\hline & Sub Urban & 12 & 24 & 5 & 10 & \\
\hline
\end{tabular}

${ }^{(*)}$ HS: Highly Sig. at $\mathrm{P}<0.01$; NS: Non Sig. at $\mathrm{P}>0.05$

Table (1) shows that the majority of the studied groups are reported at the age ranged $(20-34)$ yrs. and they are accounted $39(78 \%)$ and $40(80 \%)$ at the control and the study groups respectively. Regarding level of "Education-wife", the greater number of them illustrated low levels of education, such as illiterate, read and write, and primary schools, and they are accounted for $43(86 \%)$ and $43(86 \%)$ at the control and the study groups respectively. In addition to that, levels of "Occupationwife", the greater number of them illustrated "House wife", and they are accounted for 46(92\%) and 44(88\%) at the control and the study groups respectively. With respect to the subjects of "Residency", the majority of the sample are urban and they accounted for 32(64\%) and $36(72 \%)$ at the control and the study groups respectively. 
Table (2): Distribution of the Reproductive Information in the studied groups

\begin{tabular}{|c|c|c|c|c|c|c|}
\hline \multirow{2}{*}{$\begin{array}{l}\text { Reproductive } \\
\text { Information }\end{array}$} & \multirow{2}{*}{ Groups } & \multicolumn{2}{|c|}{ Control } & \multicolumn{2}{|c|}{ Study } & \multirow{2}{*}{$\begin{array}{l}\text { C.S. (*) } \\
\text { P-value }\end{array}$} \\
\hline & & No. & $\%$ & No. & $\%$ & \\
\hline \multirow{5}{*}{ Number of Gravid } & $1-2$ & 11 & 22 & 7 & 14 & \multirow{5}{*}{$\begin{array}{c}\text { C.C. }=0.226 \\
\mathrm{P}=0.249 \\
\mathrm{NS}\end{array}$} \\
\hline & $3-4$ & 19 & 38 & 27 & 54 & \\
\hline & $5-6$ & 12 & 24 & 12 & 24 & \\
\hline & $7-8$ & 7 & 14 & 2 & 4 & \\
\hline & $\geq 9$ & 1 & 2 & 2 & 4 & \\
\hline \multirow{4}{*}{ Number of Parity } & $<2$ & 16 & 32 & 11 & 22 & \multirow{4}{*}{$\begin{array}{c}\text { C.C. }=0.148 \\
\mathrm{P}=0.526 \\
\mathrm{NS}\end{array}$} \\
\hline & $3-4$ & 19 & 38 & 25 & 50 & \\
\hline & $5-6$ & 14 & 28 & 12 & 24 & \\
\hline & $\geq 7$ & 1 & 2 & 2 & 4 & \\
\hline \multirow{4}{*}{ Number of Abortion } & Non Abortion & 41 & 82 & 42 & 84 & \multirow{4}{*}{$\begin{array}{c}\text { C.C. }=0.100 \\
\mathrm{P}=0.798 \\
\mathrm{NS}\end{array}$} \\
\hline & one time & 5 & 10 & 5 & 10 & \\
\hline & two times & 3 & 6 & 3 & 6 & \\
\hline & three times & 1 & 2 & 0 & 0 & \\
\hline
\end{tabular}

${ }^{(*)}$ HS: Highly Sig. at $\mathrm{P}<0.01$; S: Sig. at $\mathrm{P}>0.05$; NS: Non Sig. at $\mathrm{P}>0.05$

Table (2) shows that "Number of Gravid", the vast majority of the two groups are registered at second and third groups, and they are accounted $31(62 \%)$, and $39(68 \%)$ in the control and the study groups respectively. Relative to subject's "Number of Parity ", the vast majority of the two groups are registered at second group, and they are accounted $19(38 \%)$, and $25(50 \%)$ in the control and the study groups respectively. Relative to subject's "Number of abortion ", the vast majority of the two groups are registered at none abortion, and they are accounted $41(82 \%)$, and $42(84 \%)$ in the control and the study groups respectively.

Table (3): Evaluate the effectiveness of the instructions care (for their newborn) during the postpartum period after Cesarean section

\begin{tabular}{|c|c|c|c|c|c|c|c|c|}
\hline Items & Sample & GMS & SD & RS & P-v. & T test & d.f. & P-v. \\
\hline \multirow{2}{*}{ Crying Baby } & Control & 2.34 & 0.23 & 77.9 & \multirow{2}{*}{0.263} & \multirow{2}{*}{-12.8} & \multirow{2}{*}{98.0} & \multirow{2}{*}{$\begin{array}{c}0.000 \\
\text { HS }\end{array}$} \\
\hline & Study & 2.91 & 0.21 & 97.0 & & & & \\
\hline \multirow{2}{*}{$\begin{array}{l}\text { The newborn's environment after } \\
\text { delivery }\end{array}$} & Control & 2.14 & 0.23 & 71.5 & \multirow{2}{*}{0.080} & \multirow{2}{*}{-16.6} & \multirow{2}{*}{95.7} & \multirow{2}{*}{$\begin{array}{c}0.000 \\
\text { HS }\end{array}$} \\
\hline & Study & 2.86 & 0.20 & 95.3 & & & & \\
\hline \multirow{2}{*}{ Daily hygiene } & Control & 1.34 & 0.39 & 44.8 & \multirow{2}{*}{0.531} & \multirow{2}{*}{-19.1} & \multirow{2}{*}{98.0} & \multirow{2}{*}{$\begin{array}{c}0.000 \\
\text { HS }\end{array}$} \\
\hline & Study & 2.73 & 0.33 & 91.0 & & & & \\
\hline \multirow{2}{*}{$\begin{array}{l}\text { Maintaining the health of the } \\
\text { umbilical cord }\end{array}$} & Control & 1.68 & 0.27 & 56.0 & \multirow{2}{*}{0.002} & \multirow{2}{*}{-24.1} & \multirow{2}{*}{84.8} & \multirow{2}{*}{$\begin{array}{c}0.000 \\
\text { HS }\end{array}$} \\
\hline & Study & 2.80 & 0.18 & 93.3 & & & & \\
\hline \multirow{2}{*}{ To maintain the baby's temperature } & Control & 2.75 & 0.58 & 91.7 & \multirow{2}{*}{0.000} & \multirow{2}{*}{-3.0} & \multirow{2}{*}{49.0} & \multirow{2}{*}{$\begin{array}{c}0.004 \\
\text { HS }\end{array}$} \\
\hline & Study & 3.00 & 0.00 & 100 & & & & \\
\hline \multirow{2}{*}{$\begin{array}{l}\text { Protect the newborn from infection } \\
\text { of the respiratory system }\end{array}$} & Control & 1.80 & 0.35 & 60.1 & \multirow{2}{*}{0.763} & \multirow{2}{*}{-7.1} & \multirow{2}{*}{98.0} & \multirow{2}{*}{$\begin{array}{c}0.000 \\
\text { HS }\end{array}$} \\
\hline & Study & 2.29 & 0.34 & 76.3 & & & & \\
\hline \multirow{2}{*}{ Newborn Nutrition } & Control & 1.74 & 0.23 & 58.0 & \multirow{2}{*}{0.686} & \multirow{2}{*}{-23.8} & \multirow{2}{*}{98.0} & \multirow{2}{*}{$\begin{array}{c}0.000 \\
\text { HS }\end{array}$} \\
\hline & Study & 2.84 & 0.24 & 94.7 & & & & \\
\hline \multirow{2}{*}{$\begin{array}{l}\text { Evaluate the effectiveness of the } \\
\text { instructions (for the newborn) }\end{array}$} & Control & 0.41 & 0.12 & 40.6 & 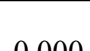 & 110 & 565 & 0.000 \\
\hline & Study & 0.04 & 0.07 & 4.00 & 0.000 & -11.9 & 50.5 & HS \\
\hline
\end{tabular}


Table (3) The results shows that a highly significant differences at $\mathrm{P}<0.01$ had illustrated between the studied groups with highly improvements due to effectiveness of the instructions care for their children during the postpartum period after Cesarean section at the study group, as well as extremely good effectiveness for the instruction

\section{Discussions}

Regarding to Socio Demographic Characteristic: (Table 1): The results show that the highest percentages (78\%) \& (80\%) respectively for both control and study groups are (20-34) years old. This finding is in agreement with a study that found that the mean age of mothers was 26.8 years. Most of the mothers (61.4\%) were in the age range of (20-24) years ${ }^{(4)}$. The highest percentages $(86 \%)$ respectively for both study and control groups are illiterate, read and write, and primary schools graduates. This finding is in agreement with study that finds that the lowest educated had the highest risk of cesarean section, followed by the medium educational mothers, and the differences gradually increased during 1967-2004 (5). The height significances in occupational status of wife, are "Housewives", and they are accounted (92\%) \& (88\%) at control and study groups, respectively this finding is constant with study that found that the factors such as educational and occupational status, family type, place of residence and economic status were found to be insignificant ${ }^{(6)}$, the vast majority (64\%) and (72\%) for both control and the study groups respectively study that found the residence association between enhancement of knowledge was non-significant and highest percent $(54 \%)$ of respondents were from rural areas ${ }^{(7)}$.

Reproductive Information in the studied: In relation to Gravid, the control and study groups accounted (62\%), and (68\%) respectively at (3-4) (56) pregnancy. Relative to "Parity " $(38 \%) \&(50 \%)$ in control and study groups respectively are registered at (3-4) deliveries. In relation to number of abortion reported none at (82\%) and (84\%) in control and study groups respectively. these finding in agreement with study that shows significant association between parity and the level of knowledge and practices followed and was found that Multipara mothers had better practices compared to postnatal mothers ${ }^{(8)}$.

Effectiveness of the instructions care (for their newborn): Table (3) The results shows that a highly significant differences at $\mathrm{P}<0.01$ had illustrated between the studied groups with highly improvements due to effectiveness of the instructions care for their newborn during the postpartum period after cesarean section at the study group, as well as extremely good effectiveness for the instructions. These instructions are in agreement with recommendations of world health organization (WHO) that include " appropriate clothing of the baby for ambient temperature, which means one to two layers of clothes more than adults, and use of hats/caps. The mother and baby should not be separated and should stay in the same room 24 hours a day'. And it recommended about cord care which include "cord should be clean, dry for newborns born in health facilities and at home in low neonatal mortality settings. Use of chlorhexidine in these situations may be considered only to replace application of a harmful traditional substance, such as cow dung, to the cord stump due to it place newborns at in-creased risk for omphalitis" (9) .also the WHO recommended that the use of sterile cotton wool soaked in either methylated spirit, chlor-hexidine or gentian violet (1\%) to clean the cord is however still being practiced widely especially in developing countries where infection rates are high (1). In relation to newborn's nutrition it recommended that all babies should be exclusively breastfed from birth until 6 months of age. Mothers should be counselled and provided support for exclusive breast feeding at each postnatal contact ${ }^{(9)}$. Also The findings agreement with descriptive studyin Iraqi (2011) at Kirkuk governorate that instruction about breast feeding which includes (Starting breastfeeding for the baby, colostrum, the best position for mother while feeding and Duration of breastfeeding) are extremely good effectiveness ${ }^{(10)}$. In addition is agreement with another Iraqi study (2012) at Baghdad governorate which ensure that health workers providing breastfeeding support \& receive education appropriate to their role in breastfeeding in order to develop the knowledge, skill and attitude to implement breastfeeding policy \& to support lactating mothers. And breastfeeding counseling for women during pregnancy and after childbirth especially who have cesarean section which has important role on maintenance of breastfeeding up to 6 months ${ }^{(11)}$. Multiple behaviors that, if initiated during the postpartum period, would promote the health of both the new mother and baby, and have an impact on the mother and newborn's health after delivery need to be initiated earlierduring pregnancy or at the time of labor or delivery ${ }^{(12)}$ .A descriptive cross sectional study was conducted in pediatric unit concluded that education of women were the important factors associated with a good practices 
in breast feeding and thermal care practices however in cord care and newborn hygiene were poor ${ }^{(13)}$.Finally, Study conduct in Nepal (2012) Successful development and implementation of a newborn care package of these mostly behavior change strategies will require cultural and contextual adaptation and emphasis during the antenatal period, at birth, through the neonatal period. To reduce infections and improve developmental outcomes, and to increase appropriate care that could contribute to substantial reduction in neonatal mortality ${ }^{(14)}$.

Recommendation: The study recommended that nurses should teach women delivered by cesarean section the principle practice regarding newborn care, also recommended on mass media to take an action to keep the mother informed about practice regarding newborn care.

\section{Conflict of Interest: Nil}

Source of Funding: The source of funding is self

Ethical Clearance: is obtained from the Ministry of Health/Al-Russafa Health Directorate (Baghdad Teaching Hospital), and All laboring women participants in the research-have been approved before the questionnaire is started.

\section{References}

1. WHO recommendations on newborn health: guidelines approved by the WHOGuidelines Review Committee. Geneva: World Health Organization; (WHO/MCA/17.07). Licence: CC BY-NC-SA 3.0 IGO. 2017

2. Nour N. An Introduction to Maternal Mortality. Reviews in Obstetrics \& Gynecology, (2008.), (1):77-81.

3. WHO.WHO Recommendations on Postnatal Care of the Mother and Newborn. October 2013. Geneva: WHO)

4. Abdissa, Z., Awoke, T., Belayneh, T., \& Tefera, $Y$. Birth outcome after caesarean section among mothers who delivered by caesarean section under general and spinal anesthesia at Gondar University teaching hospital north-west Ethiopia.(2013).
5. Tollånes, M. C., Thompson, J. M., Daltveit, A. K., \& Irgens, L. MCesarean section and maternal education; secular trends in Norway, 1967-2004. Acta obstetricia et gynecologica Scandinavica, (2007), 86(7), 840-848.

6. Kiliç, M.. The delivery method and the factors affecting among giving birth in hospitals in Yozgat, Turkey. International Journal of Caring Sciences, (2012), 5(2), 157-161.

7. Sukanya: A study to evaluate the effectiveness of self-instructional module regarding perineal care in primipara postnatal mothers at selected hospital, Bangalore. . MSc, Rajiv Gandhi University of Health Sciences, Karnataka, Bangalore, (2005).

8. Priya K.: a Study to Assess the Knowledge and Practice on Selected Aspects of Postnatal Care Among Postnatal Mothers in Kempa Cheluvamba General Hospital, Malleswaram, Bangalore, (2004).

9. WHO.WHO Recommendations on Postnatal Care of the Mother and Newborn. April, 2015. Geneva: WHO.

10. Mahmud, N. A.. Knowledge of Breastfeeding: A descriptive study among mothers in Kirkuk Governorate. Nursing national Iraqi specialty, (2011), 24(2), 84-93.

11. Hasan, R. T., \& Abass, I. MEffectiveness of lactation counseling on maintenance of breastfeeding. nursing national Iraqi specialty, (2012), 25(3), 2034..

12. Koblinsky, M. A. Community-based postpartum care: an urgent unmet need. Washington DC, USA: USAID, The CATALYST Consortium. (2005).

13. Chhetri, B. T., Bhandari, S. S., Karna, B. K., Chaudhary, R., \& Yadav, U. Newborn Care Practices at Home among Mothers of Neonates Admitted with Sepsis. Religion, -(2019),29, 72.

14. Karas, D. J., Mullany, L. C., Katz, J., Khatry, S. K., LeClerq, S. C., Darmstadt, G. L., \& Tielsch, J. M. Home care practices for newborns in rural southern Nepal during the first 2 weeks of life. Journal of tropical pediatrics, (2012), 58(3), 200-207. 